\title{
Thermogravimetric Study of Dehydration and Thermal Degradation of Gypsum Board at Elevated Temperatures
}

\author{
MARC JANSSENS \\ Southwest Research Institute \\ 6220 Culebra Road \\ San Antonio, TX 78258 USA
}

\begin{abstract}
Over the past few years a growing number of investigators have used parameter estimation techniques based on genetic algorithms to determine material properties for pyrolysis modeling from small-scale test data. Southwest Research Institute is exploring the use of these techniques to determine material properties needed for computer modeling to predict the behavior of structures in a fire. This paper focuses on the kinetic parameters that are needed to predict dehydration and thermal degradation of gypsum board using a set of Arrhenius equations. Specimens of a Type $\mathrm{C}$ board were tested in a TGA apparatus in nitrogen at four heating rates; $5,10,20$ and $60{ }^{\circ} \mathrm{C} / \mathrm{min}$. A more conventional approach was used instead of a genetic algorithm to determine the parameters from the TGA data. This approach is implemented on a spreadsheet and is much easier to use than optimization techniques based on genetic algorithms. In many cases it may provide a good, albeit less versatile, alternative. Initially, reactions that occur in temperature ranges that overlap were lumped into a single reaction. At the end of the paper an attempt is made to separate overlapping reactions and estimate the kinetic parameters for each of the overlapping reactions separately.
\end{abstract}

KEYWORDS: gypsum board, kinetic constants, parameter estimation, modeling, TGA.

\section{NOMENCLATURE LISTING}

$A$ pre-exponential factor (1/s)

$E \quad$ activation energy $(\mathrm{kJ} / \mathrm{mol})$

$M$ number of data points

$m$ specimen mass (mg)

$N$ number of active components

$n$ reaction order

$R \quad$ universal gas constant $(8.3145 \mathrm{~J} / \mathrm{mol} \cdot \mathrm{K})$

$T$ temperature (K)

$T$ time (s)

$Y$ mass fraction

$\begin{array}{ll}\text { Greek } & \\ \alpha & \text { conversion }(\%) \\ \beta & \text { heating rate }\left({ }^{\circ} \mathrm{C} / \mathrm{min} \text { or }{ }^{\circ} \mathrm{C} / \mathrm{s}\right) \\ \varepsilon & \text { error } \\ \rho & \text { density }\left(\mathrm{kg} / \mathrm{m}^{3}\right) \\ \text { subscripts } \\ o \quad \text { initial } \\ i & \text { component index } \\ j & \text { data point index } \\ f & \text { final }\end{array}$

\section{INTRODUCTION}

Over the past few years a growing number of investigators have used parameter estimation techniques based on genetic algorithms (GA) to determine material properties for pyrolysis modeling from small-scale test data [1-6]. Southwest Research Institute is exploring the use of these techniques to determine material properties needed for computer modeling to predict the behavior of structures in a fire.

Unfortunately, optimization based on GA is not trivial and it takes considerable effort and experience to set up and streamline the GA parameter estimation process. It was therefore decided to also explore a more conventional parameter estimation technique as an alternative or as a tool to obtain suitable starting values for the GA iterations.

The first step of the process generally involves analysis of a series of thermogravimetric analysis (TGA) tests to determine the kinetic parameters for the Arrhenius reactions describing the thermal degradation of the material. This paper focuses on that step in the process. TGA tests were conducted at different heating rates on specimens of the core of a well-characterized fire-rated gypsum board material. Gypsum board was chosen because its behavior in fires has been studied extensively and its properties are relatively well known [7-15]. 


\section{THERMOGRAVIMETRIC ANALYSIS}

Changes in mass of a material as function of temperature are most conveniently measured through TGA. A TGA apparatus consists of a high-precision balance with a pan (usually aluminum, platinum or ceramic) loaded with the specimen. The specimen mass is typically of the order of a few milligrams. It is kept as small as possible (to ensure uniform temperature) and depends on the material that is tested. The specimen pan is placed in a small computer-controlled furnace with a thermocouple to accurately measure the temperature. The atmosphere may be purged with an inert gas (e.g. nitrogen or argon) to prevent oxidation or other undesired reactions. During a test, the furnace temperature is either kept constant or increased at a fixed rate (typically between 1 and $60{ }^{\circ} \mathrm{C} / \mathrm{min}$ ) to predefined maximum temperature (routinely $1000{ }^{\circ} \mathrm{C}$ or higher). The heating rate affects the rate of thermal decomposition of a material and a faster heating rate tends to push the mass loss curve to higher temperatures. The result consists of a plot of mass (percentage) and/or mass loss rate as a function of time and/or temperature (see Fig. 1 for an example).

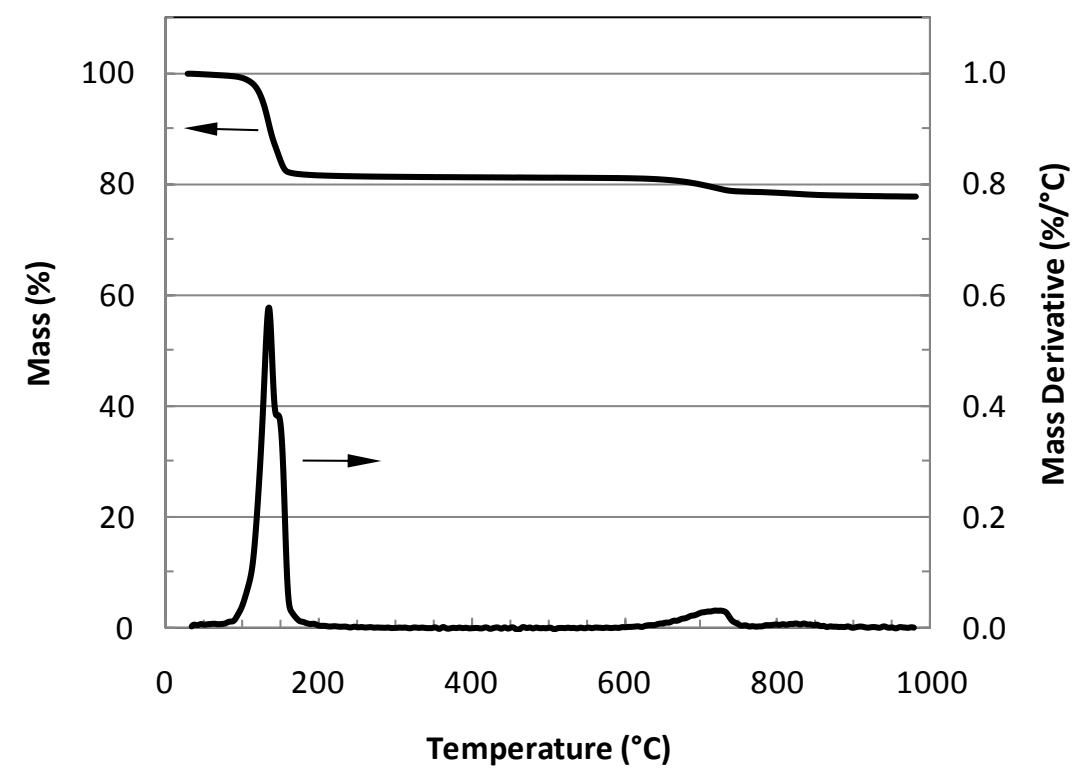

Fig. 1. Example of TGA mass and mass loss rate curves (Type $\mathrm{C}$ gypsum board heated at $20{ }^{\circ} \mathrm{C} / \mathrm{min}$ ).

\section{ARRHENIUS-RATE THERMAL DECOMPOSITION KINETICS}

Consider an experiment in which a (small) specimen of a material that is heated uniformly so that its temperature $T$ rises with increasing time $t$. It is assumed that the material consists of $N+1$ components. The mass fractions of the components are denoted as $Y_{0}, Y_{l}, \ldots Y_{N}$. By convention the first component (index 0 ) is considered to be inert, i.e., the mass of this component does not change as the temperature of the material rises. Some materials do not comprise an inert component, in which case $Y_{0}=0$. The remaining components degrade with increasing temperature, i.e. a part is gradually converted from a solid to a gas. The following equation can then be used to express the time-varying mass of the specimen as a function of the mass fractions of the $N$ components:

$m(t)=\left[Y_{0}+\sum_{i=1}^{N} Y_{i}(t)\right] m_{0}$.

The rate at which the conversion of the active components $(i=1,2, \ldots N)$ takes place can often be described with remarkable accuracy by an Arrhenius equation: 


$$
\frac{d \alpha_{i}(t)}{d t}=f\left(\alpha_{i}(t)\right) A_{i} \exp \left(-\frac{E_{i}}{R T}\right)
$$

where the conversion $\alpha_{i}$ is given by

$$
\alpha_{i}(t)=\frac{Y_{i, 0}-Y_{i}(t)}{Y_{i, 0}-Y_{i, f}} .
$$

The value of $\alpha_{i}$ is initially equal to zero and gradually changes to one as the material is heated and the component converted to its final state. Equation 2 is not only suitable to model chemical reactions associated with thermal degradation, but also works well to mathematically describe pertinent physical phenomena such as moisture desorption and evaporation. The function $f$ is often assumed to be of the following form:

$$
f\left(\alpha_{i}(t)\right)=\left(1-\alpha_{i}(t)\right)^{n_{i}} .
$$

Using Eqs. 1 and 3, the conversion rate of the material can then be expressed as follows

$$
\frac{d m(t)}{d t}=\frac{d\left(\sum_{i=1}^{N} m_{0} Y_{i}(t)\right)}{d t}=m_{0} \sum_{i=1}^{N} \frac{d Y_{i}(t)}{d t}=-m_{0} \sum_{i=1}^{N}\left(Y_{i, 0}-Y_{i, f}\right) \frac{d \alpha_{i}(t)}{d t} .
$$

Based on Eqs. 2, 4 and 5 the relative mass loss rate is given by

$$
\frac{d\left(m(t) / m_{0}\right)}{d t}=-\sum_{i=1}^{N}\left(Y_{i, 0}-Y_{i, f}\right)\left(1-\alpha_{i}(t)\right)^{n_{i}} A_{i} \exp \left(-\frac{E_{i}}{R T}\right) \text {. }
$$

\section{ESTIMATING KINETIC PARAMETERS FROM THERMOGRAVIMETRIC DATA}

The simplified method to obtain kinetic parameters from one or a set of TGA curves used in this study was developed by Vandevelde [16]. Combination of Eqs. 2 and 4 leads to

$$
\frac{d \alpha_{i}(t)}{d t}=\left(1-\alpha_{i}(t)\right)^{n_{i}} A_{i} \exp \left(-\frac{E_{i}}{R T}\right) .
$$

Taking the natural logarithm of both sides of Eq. 7 results in

$$
\ln \left(\frac{d \alpha_{i}(t)}{d t}\right)=n_{i} \ln \left(1-\alpha_{i}(t)\right)+\ln \left(A_{i}\right)-\frac{E_{i}}{R T} .
$$

Equation 8 can be expressed at each time $t_{j}$ at which mass and temperature data are collected. Since the TGA measurements are subject to error and because Eq. 7 may not be exact, there is a (slight) difference between the two sides of Eq. 8. If this error at time $t_{j}$ is denoted as $\varepsilon_{j}$ and the conversion and the temperature at that time are written as $\alpha_{I, j}$ and $T_{j}$ respectively, the following equation is obtained: 
$n_{i} \ln \left(1-\alpha_{i, j}\right)+\ln \left(A_{i}\right)-\frac{E_{i}}{R T_{j}}-\ln \left(\frac{d \alpha_{i}}{d t}\right)_{j}=\varepsilon_{j}$

The values for $n_{i}, A_{i}$ and $E_{i}$ that result in the best fit of the Arrhenius equation to the data can now be obtained by minimizing the sum of the squares of $\varepsilon_{j}$ for all (or a subset of) the data points in the temperature range over which component $i$ reacts. In other words, the best-fitting values of $n_{i}, A_{i}$ and $E_{i}$ can be found by solving the following set of equations:

$$
\begin{aligned}
& \frac{\partial\left(\sum_{j=1}^{M_{i}} \varepsilon_{j}^{2}\right)}{\partial\left(\ln \left(A_{i}\right)\right)}=2 \sum_{j=1}^{M_{i}}\left[\ln \left(A_{i}\right)+n_{i} \ln \left(1-\alpha_{i, j}\right)-\frac{E_{i}}{R T_{j}}-\ln \left(\frac{d \alpha_{i}}{d t}\right)_{j}\right]=0 \\
& \frac{\partial\left(\sum_{j=1}^{M_{i}} \varepsilon_{j}^{2}\right)}{\partial\left(n_{i}\right)}=2 \sum_{j=1}^{M_{i}}\left[\ln \left(A_{i}\right)+n_{i} \ln \left(1-\alpha_{i, j}\right)-\frac{E_{i}}{R T_{j}}-\ln \left(\frac{d \alpha_{i}}{d t}\right)_{j}\right] \ln \left(1-\alpha_{i, j}\right)=0 \\
& \frac{\partial\left(\sum_{j=1}^{M_{i}} \varepsilon_{j}^{2}\right)}{\partial\left(-E_{i} / R\right)}=2 \sum_{j=1}^{M_{i}}\left[\ln \left(A_{i}\right)+n_{i} \ln \left(1-\alpha_{i, j}\right)-\frac{E_{i}}{R T_{j}}-\ln \left(\frac{d \alpha_{i}}{d t}\right)_{j}\right] \frac{1}{T_{j}}=0
\end{aligned}
$$

or

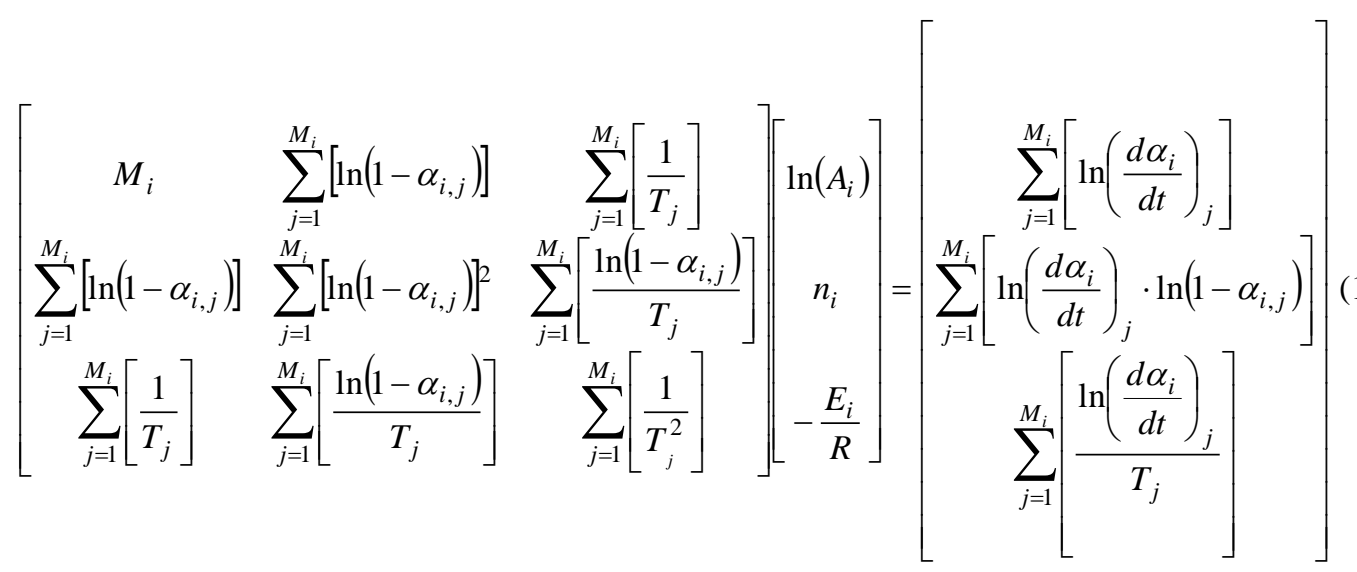

If the temperature ranges for the reactions of the different components are separated, $\alpha_{i, j}$ can be calculated directly from the initial and final mass (i.e., the specimen mass measured in the TGA before the reaction begins and after it is completed) and the mass at time $t_{j}$.

Vandevelde suggests not including all data points over the temperature range over which the component reacts in the summations, but only using data points at equally spaced conversions. In this study we chose 18 data points, two each around $10 \%, 20 \%, 30 \%, 40 \%, 50 \%, 60 \%, 70 \%, 80 \%$ and $90 \%$ conversion. This ensures the best fit over the temperature range over which most of the mass is lost $(10 \%$ to $90 \%$ conversion) and ignores the initial and final phases of the reaction when not much is happening. This is illustrated in Fig. 2, which shows the 18 data points for the temperature range corresponding to the first peak of the mass loss rate in Fig. 1. The mass loss over this temperature range is attributed to a single 
reaction. Figure 2 also shows the best fitting calculated conversion curve. The solution of Eq. 11 for this case is $n_{l}=1.48, A_{l}=7.76 \times 10^{15} 1 / \mathrm{s}$, and $E_{l}=137 \mathrm{~kJ} / \mathrm{mol}$.

Vandevelde's approach can easily be extended to find a single set of kinetic parameters that result in the best overall fit for a collection of TGA curves obtained at different heating rates. In this case the summations in Eq. 11 are simply extended over all datasets.

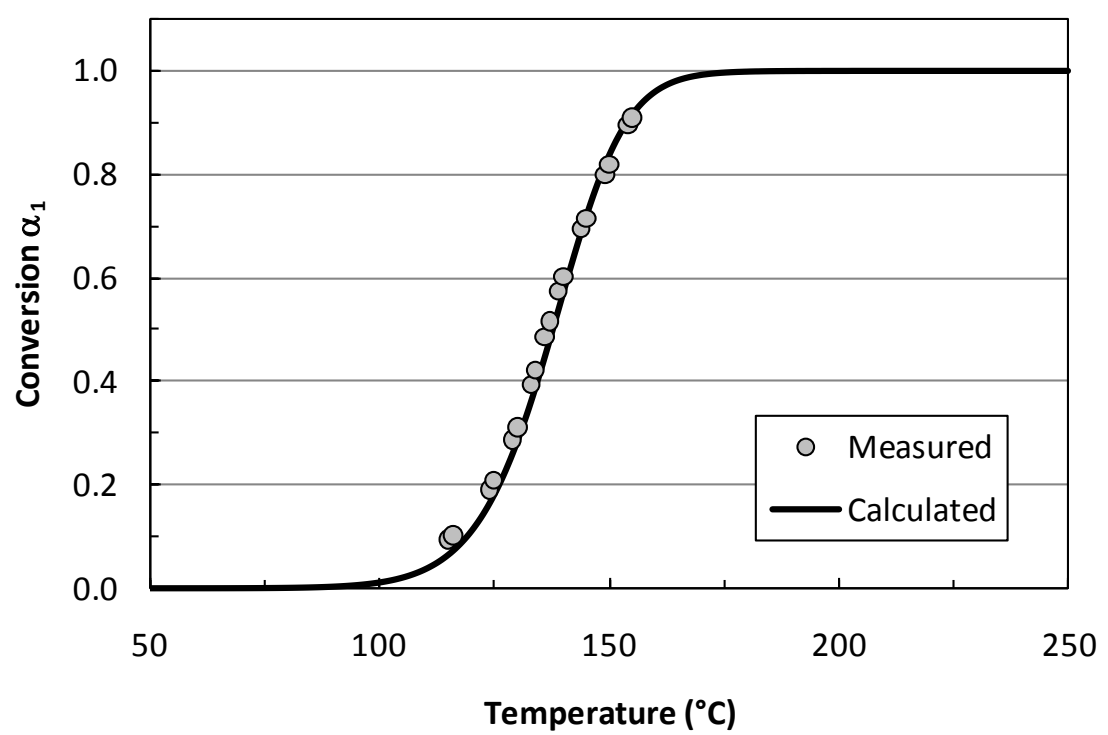

Fig. 2. Best fit of $\alpha_{1}$ for the data shown in Fig. 1.

\section{DEHYDRATION AND THERMAL DECOMPOSITION OF TYPE C GYPSUM BOARD}

\section{Material Tested}

The material that was tested in this study is a Type $\mathrm{C}$ gypsum board. The board was used previously in an inter-laboratory study [17]. A single sheet of this $16 \mathrm{~mm}$ thick board was attached on both sides of a steel frame to construct a non-loadbearing wall assembly that was tested according to ASTM E 119 in 16 laboratories; 10 in North America and 6 in Japan. Extensive small-scale testing was conducted at NIST to obtain the thermal properties of the board at elevated temperatures [13].

\section{Parameter Estimates Obtained with Vandevelde's Method}

Specimens of the gypsum core of the board conditioned to equilibrium mass in an environment at $21{ }^{\circ} \mathrm{C}$ and $50 \%$ relative humidity were tested in a TGA apparatus at SwRI in a nitrogen atmosphere at four heating rates. To determine the kinetic parameters, initially it is assumed that the first peak in the mass loss rate (see Fig. 1) is due to a single reaction. In reality this peak is the result of two overlapping reactions. At lower temperatures $\left(100-170{ }^{\circ} \mathrm{C}\right)$ the gypsum loses $75 \%$ of its bound water and is converted from calcium sulfate dihydrate to calcium sulfate hemihydrate:

$\mathrm{CaSO}_{4} \cdot 2 \mathrm{H}_{2} \mathrm{O} \rightarrow \mathrm{CaSO}_{4} \cdot \frac{1}{2} \mathrm{H}_{2} \mathrm{O}+\frac{3}{2} \mathrm{H}_{2} \mathrm{O}$

At higher temperatures $\left(130-180{ }^{\circ} \mathrm{C}\right)$ the material loses its remaining bound water and is converted to calcium sulfate anhydrate:

$$
\mathrm{CaSO}_{4} \cdot \frac{1}{2} \mathrm{H}_{2} \mathrm{O} \rightarrow \mathrm{CaSO}_{4}+\frac{1}{2} \mathrm{H}_{2} \mathrm{O}
$$


Both reactions are endothermic and produce liquid water. Another reaction occurs around $700{ }^{\circ} \mathrm{C}$. This reaction is believed to be the decarbonation of calcium carbonate $[8,10,11,15]$. Table 1 shows the initial and residual mass fractions for the two reactions (i.e. assuming that the first peak in the mass loss rate corresponds to a single dehydration reaction).

Table 1. Initial and residual component mass fractions assuming two separate reactions.

\begin{tabular}{|c|c|c|c|c|c|c|}
\hline & \multicolumn{5}{|c|}{ Initial mass fraction } & \multirow{2}{*}{$\begin{array}{c}\text { Residual } \\
\text { fraction }\end{array}$} \\
\cline { 2 - 6 } & $\mathbf{5}^{\circ} \mathbf{C} / \mathbf{m i n}$ & $\mathbf{1 0}{ }^{\circ} \mathbf{C} / \mathbf{m i n}$ & $\mathbf{2 0}^{\circ} \mathbf{C} / \mathbf{m i n}$ & $\mathbf{6 0}^{\circ} \mathbf{C} / \mathbf{m i n}$ & Average $^{\mathbf{a}}$ & 0.785 \\
\hline $\boldsymbol{Y}_{\mathbf{0}}$ & 0.790 & 0.786 & 0.780 & 0.770 & 0.785 & 0.183 \\
\hline $\boldsymbol{Y}_{\mathbf{1}}$ & 0.181 & 0.181 & 0.187 & 0.190 & 0.000 \\
\hline $\boldsymbol{Y}_{\mathbf{2}}$ & 0.029 & 0.034 & 0.034 & 0.040 & 0.032 & 0.000 \\
\hline
\end{tabular}

The mass fractions in Table 1 vary slightly according to the heating rate that was used in the TGA. Initially a single set of kinetic parameters was obtained to model the four curves. However, it was determined from this initial analysis that the mass loss measurements in the test at a heating rate of $60{ }^{\circ} \mathrm{C} / \mathrm{min}$ are shifted toward the higher temperatures. It is believed that this is due to the fact that at the highest heating rate the specimen temperature is no longer uniform. The kinetic parameters were therefore recalculated based on the mass loss measurements at 5,10 and $20{ }^{\circ} \mathrm{C} / \mathrm{min}$ only. The resulting values are given in Table 2.

Table 2. Kinetic parameters resulting in the best overall fit of $\alpha_{l}(T)$ and $\alpha_{2}(T)$.

\begin{tabular}{|c|c|c|}
\hline & Component 1 & Component 2 \\
\hline $\boldsymbol{A}$ & $2.05 \times 10^{9} 1 / \mathrm{s}$ & $1.84 \times 10^{8} 1 / \mathrm{s}$ \\
\hline $\boldsymbol{n}$ & 0.83 & 1.91 \\
\hline $\boldsymbol{E}$ & $87 \mathrm{~kJ} / \mathrm{mol}$ & $194 \mathrm{~kJ} / \mathrm{mol}$ \\
\hline
\end{tabular}

Figures $3 \mathrm{a}$ through $3 \mathrm{~d}$ compare the calculated mass loss curves to those measured in the TGA experiments. Figure $3 \mathrm{~d}$ illustrates the shift of the measured curves toward the higher temperatures, which can be explained by the fact that the specimen temperature is no longer uniform at a heating rate of $60{ }^{\circ} \mathrm{C} / \mathrm{min}$.

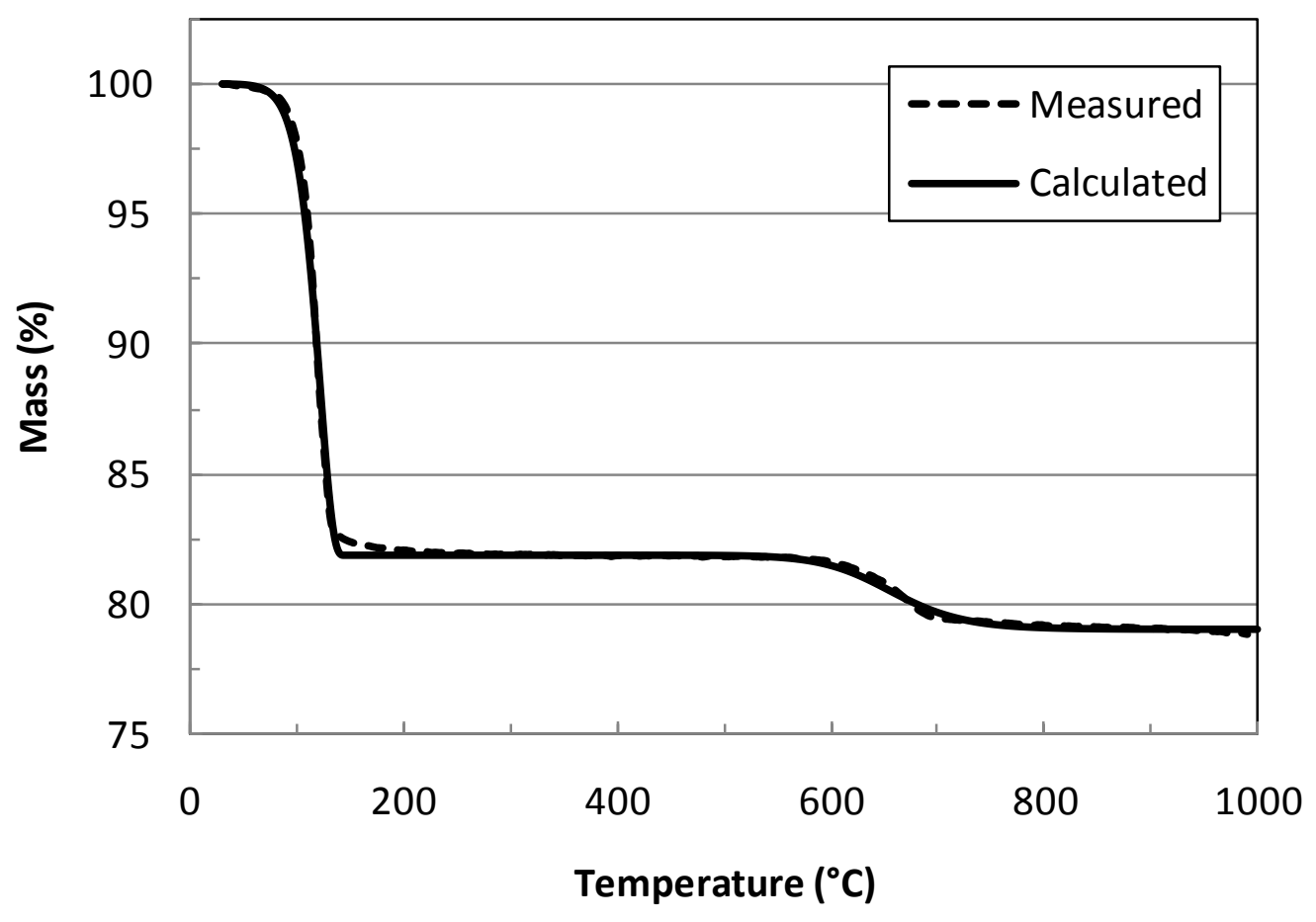

Fig. 3a. Comparison of calculated and measured mass vs. temperature at $5{ }^{\circ} \mathrm{C} / \mathrm{min}$. 


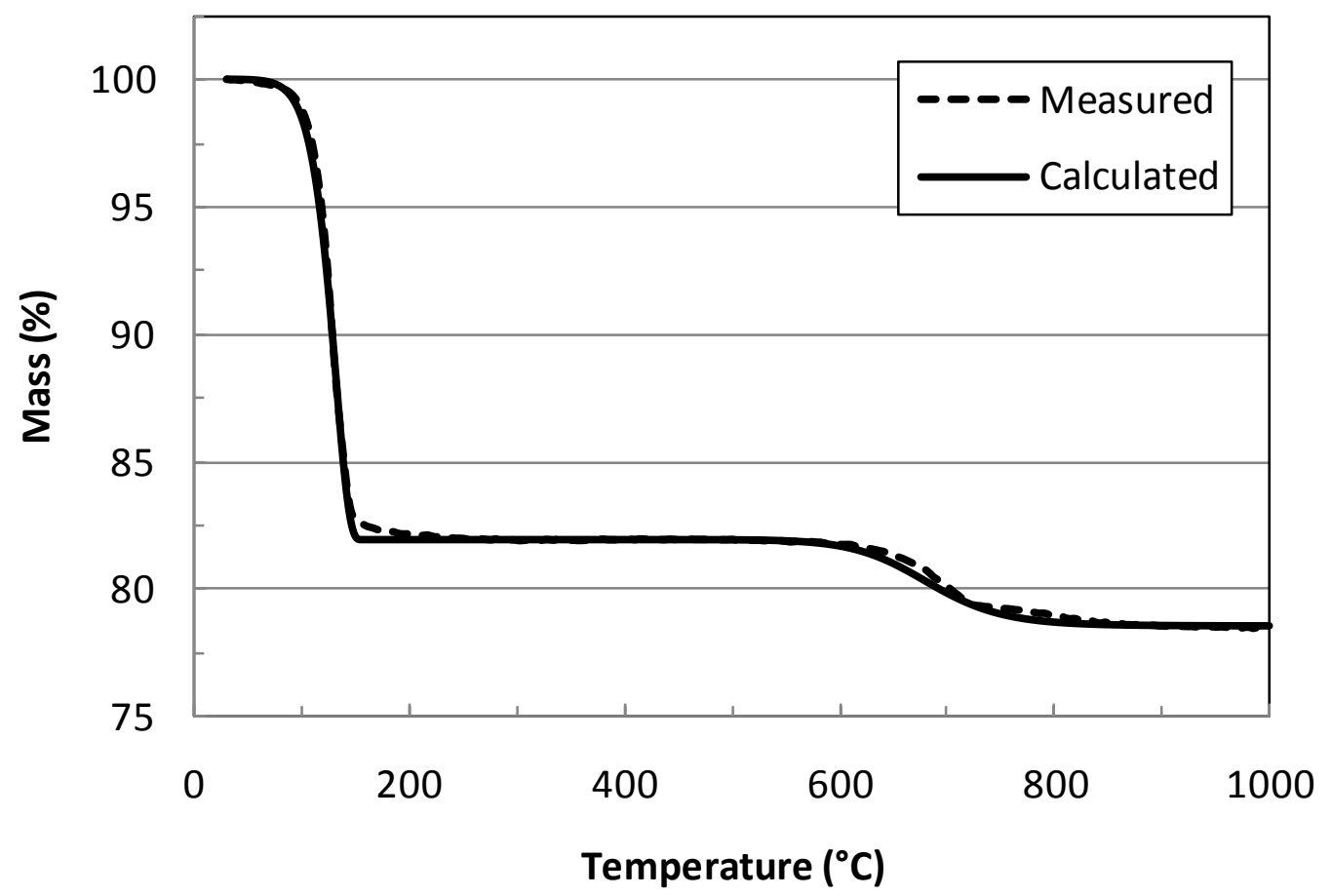

Fig. 3b. Comparison of calculated and measured mass vs. temperature at $10{ }^{\circ} \mathrm{C} / \mathrm{min}$.

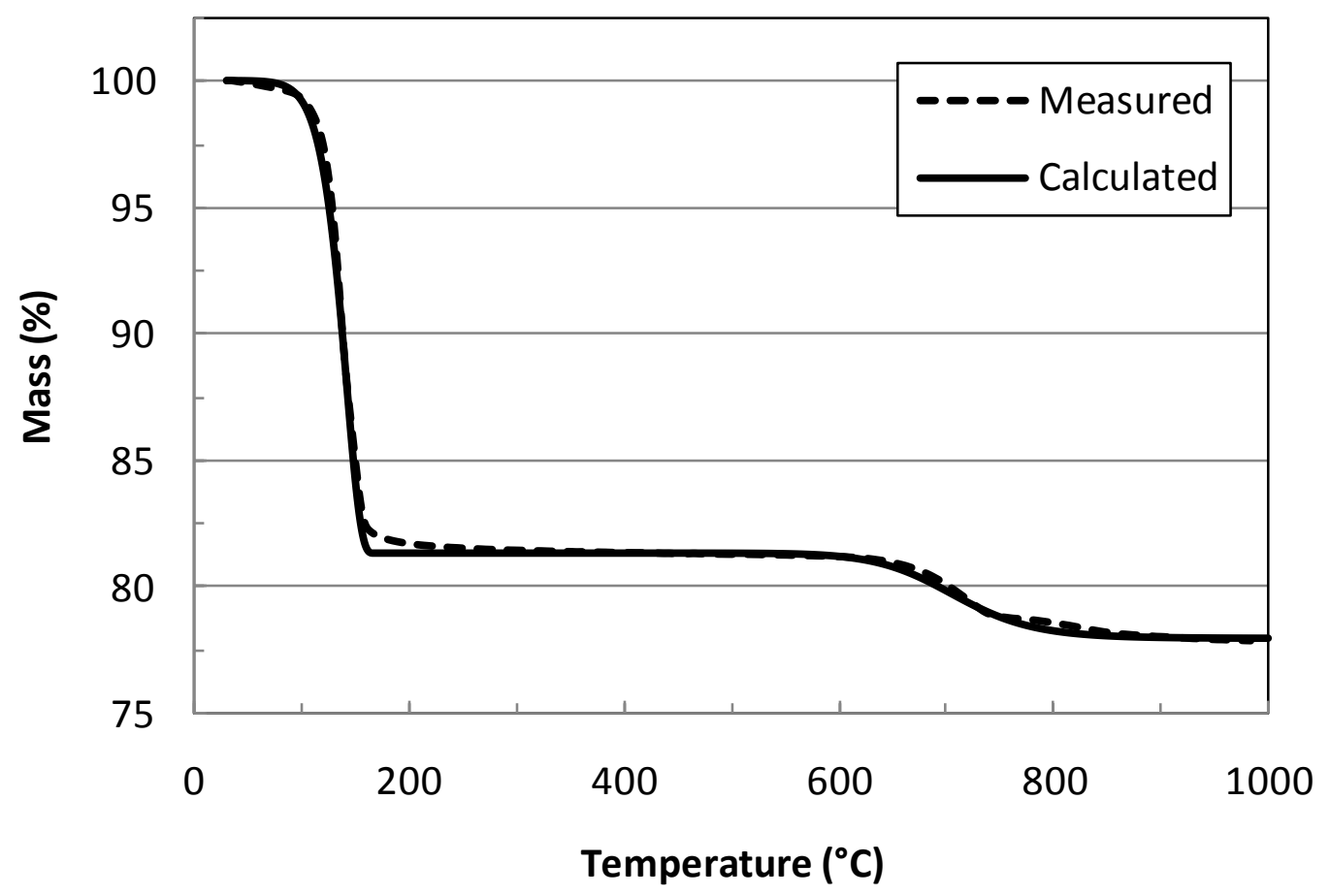

Fig. 3c. Comparison of calculated and measured mass vs. temperature at $20^{\circ} \mathrm{C} / \mathrm{min}$. 


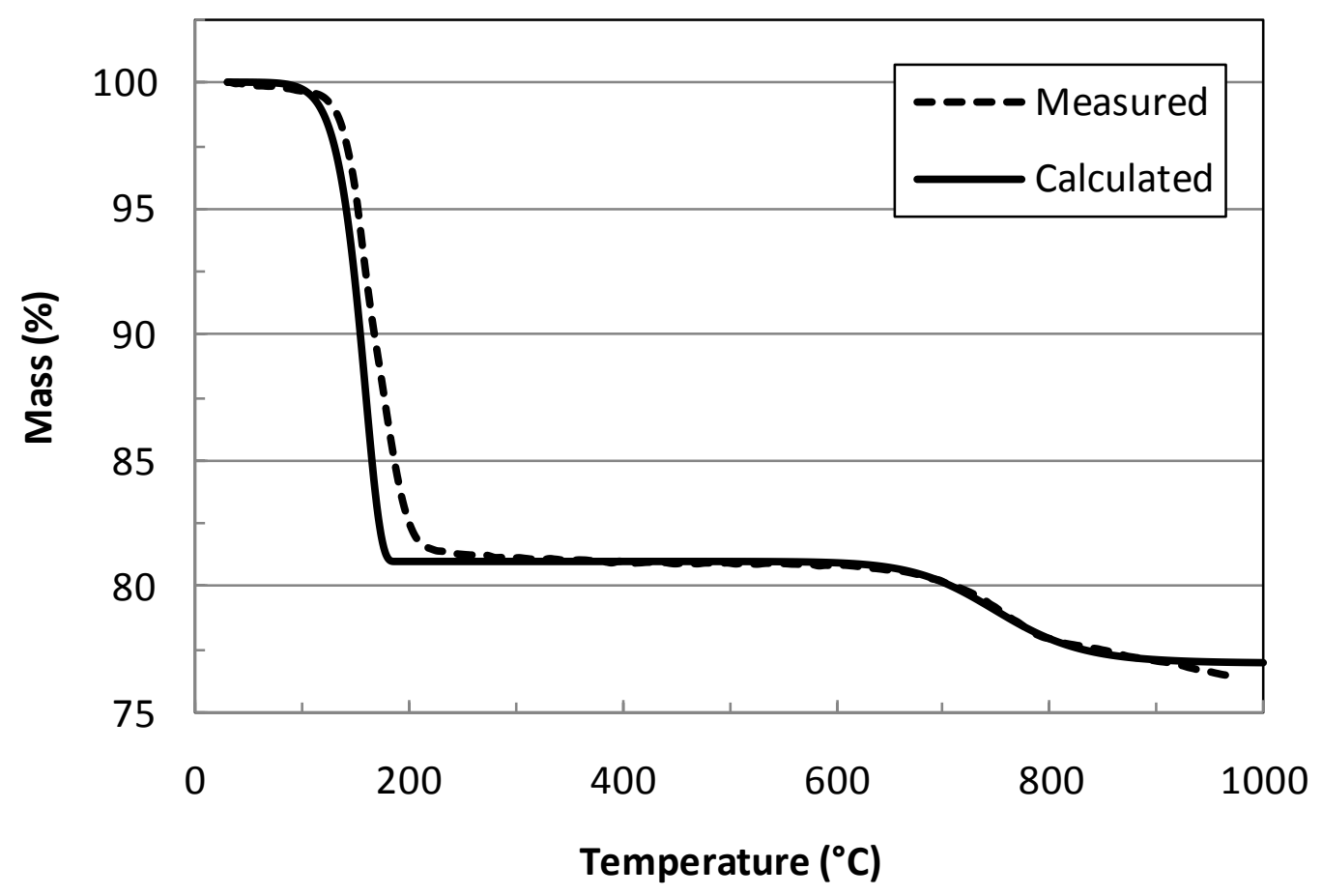

Fig. 3d. Comparison of calculated and measured mass vs. temperature at $60^{\circ} \mathrm{C} / \mathrm{min}$.

\section{OVERLAPPING REACTIONS}

Figure 4a shows a comparison between the measured and calculated mass loss rate curves at a heating rate of $20{ }^{\circ} \mathrm{C} / \mathrm{min}$, as an example. It is not so clear from this figure that the measured mass loss rate curve has two distinct peaks, but this becomes rather obvious when zooming in on the temperature range between 50 and $250{ }^{\circ} \mathrm{C}$ as shown in Fig. 4b. To predict the mass loss rate with higher accuracy it is necessary to separate the two dehydration reactions. Unfortunately this is not possible since only the fractions of the total mass loss that can be attributed to each of the reactions are known. While the two reactions are progressing, these fractions are not known.

In an attempt to separate the dehydration reactions and improve the mass loss rate predictions is assumed that the mass loss of the dehydration reactions can be represented by a sigmoid curve:

$m_{i}(T)=m_{i, 0}-\left(m_{i, 0}-m_{i, f}\right) \frac{1}{1+\exp \left[-C_{i}\left(T-T_{\max , i}\right)\right]}$,

where $i$ is equal to 1 or $2, T_{\max }$ is the temperature at which the mass loss rate reaches a maximum and $C$ is a constant that determines the mass loss rate at $T_{\max }$. Figure 5a shows the best fitting sigmoid curves for the dehydration reactions of Type $\mathrm{C}$ gypsum board at a heating rate of $20{ }^{\circ} \mathrm{C} / \mathrm{min}$. Agreement between the combined calculated mass loss curve and the measured curve is actually not as good as in Fig. $3 \mathrm{c}$, but the combined calculated mass loss rate now shows two peaks and is in better agreement with the measured curve.

Table 3 shows the initial and residual mass fractions for the three reactions (i.e. two separate dehydration reactions and a single reaction around $700^{\circ} \mathrm{C}$ ). The calculated mass loss and mass loss rates curves based on the kinetic parameters obtained with Vandevelde's technique for the separated dehydrations reactions fall on top of the combined curves in Figs. 5a and 5b. 


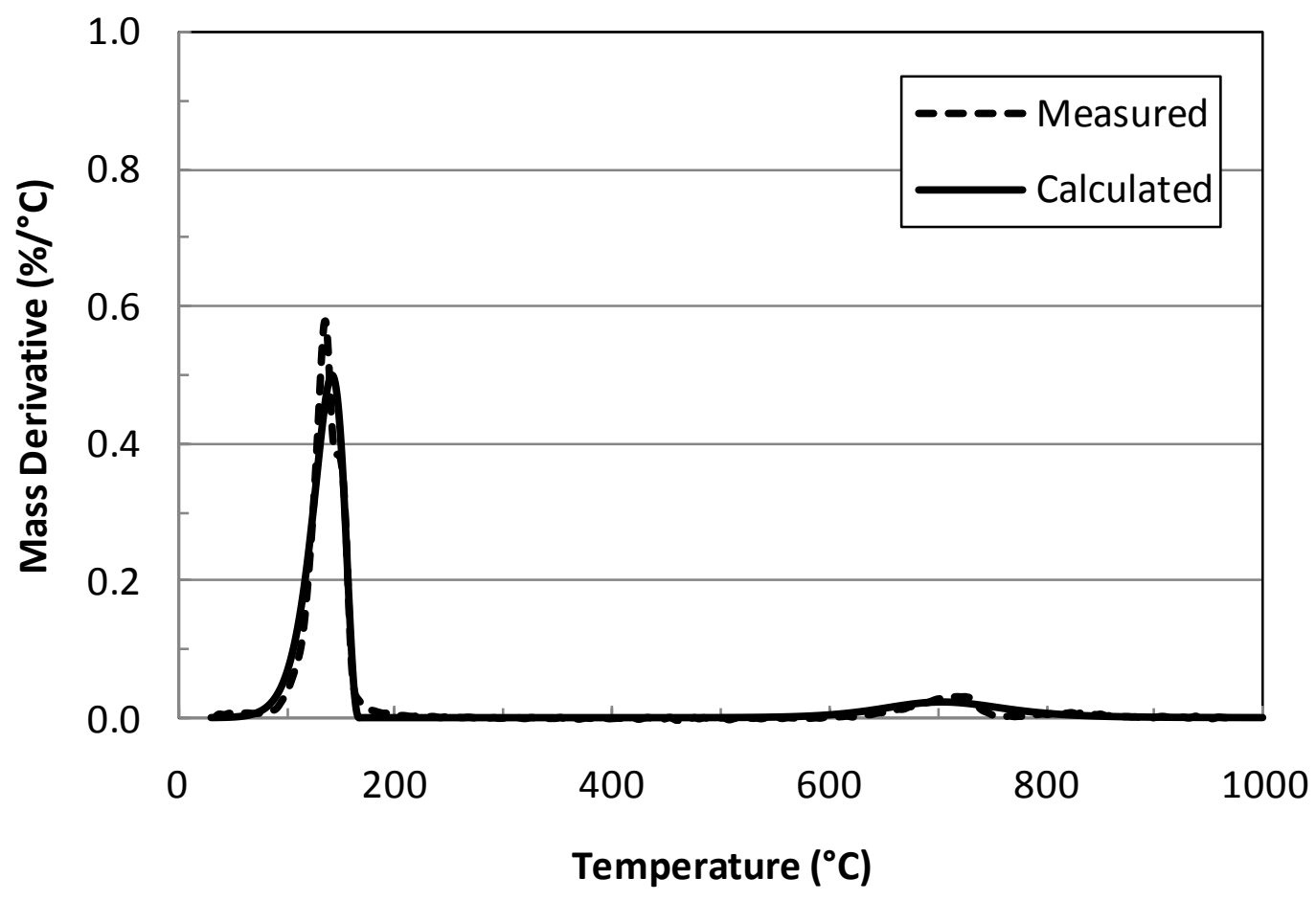

Fig. 4a. Comparison of calculated and measured mass loss rate vs. temperature at $20{ }^{\circ} \mathrm{C} / \mathrm{min}$.

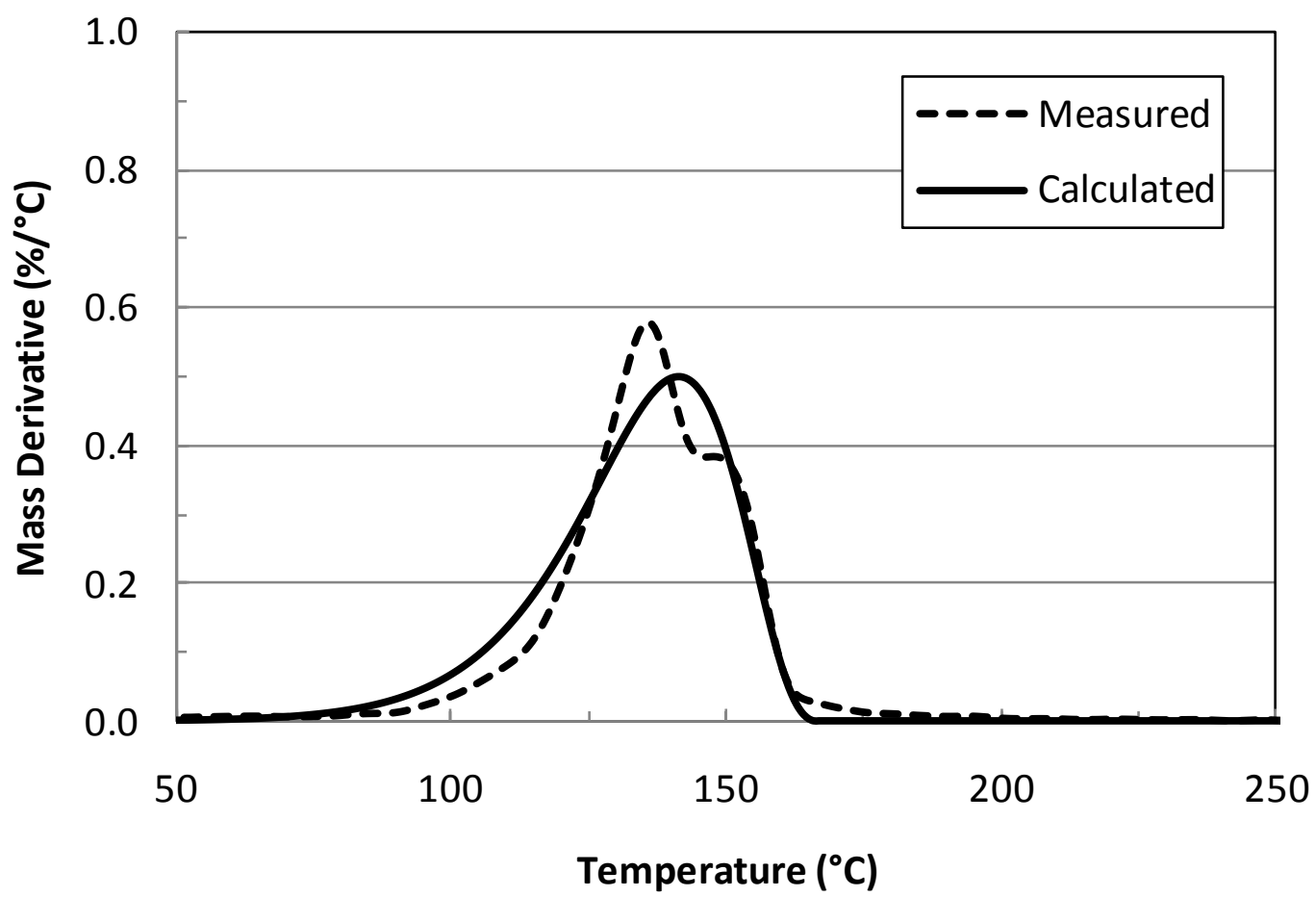

Fig. 4b. Comparison of calculated and measured mass loss rate vs. temperature at $20{ }^{\circ} \mathrm{C} / \mathrm{min}$. 


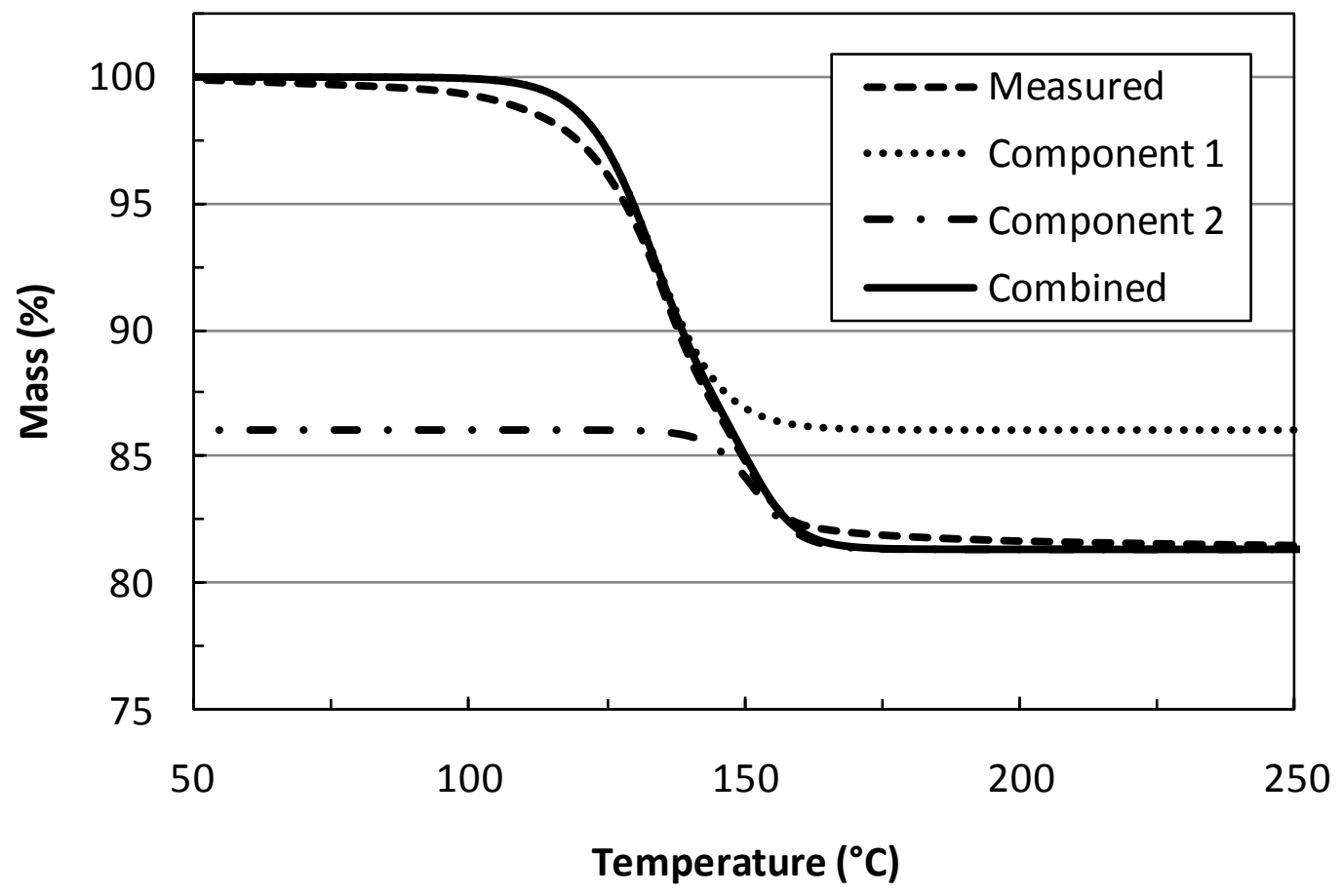

Fig. 5a. Best-fitting sigmoid curves for the two dehydration reactions of type $\mathrm{C}$ gypsum board

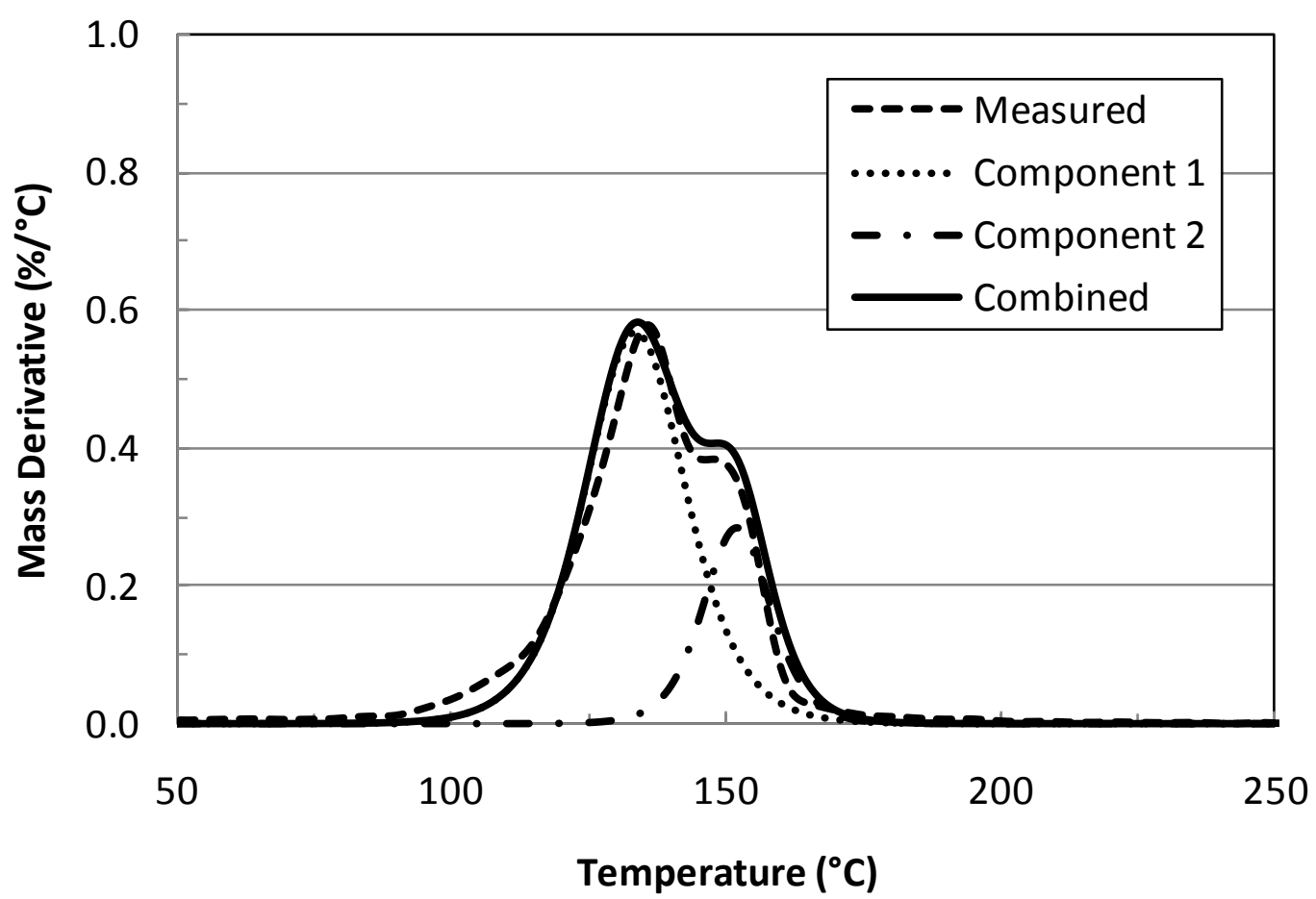

Fig. 5b. Mass loss rate curves corresponding to the sigmoid curves in Fig. 5a. 
Table 3. Initial and residual component mass fractions for three reactions.

\begin{tabular}{|c|c|c|c|c|c|c|}
\hline & \multicolumn{5}{|c|}{ Initial mass fraction } & \multirow{2}{*}{$\begin{array}{l}\text { Residual } \\
\text { fraction }\end{array}$} \\
\hline & $5^{\circ} \mathrm{C} / \mathrm{min}$ & $10{ }^{\circ} \mathrm{C} / \mathrm{min}$ & $20^{\circ} \mathrm{C} / \mathrm{min}$ & $60^{\circ} \mathrm{C} / \mathrm{min}$ & Average $^{a}$ & \\
\hline$Y_{0}$ & 0.790 & 0.786 & 0.780 & 0.770 & 0.785 & 0.785 \\
\hline$Y_{1}$ & 0.136 & 0.135 & 0.140 & 0.142 & 0.137 & 0.000 \\
\hline$Y_{2}$ & 0.045 & 0.045 & 0.047 & 0.047 & 0.046 & 0.000 \\
\hline$Y_{3}$ & 0.029 & 0.034 & 0.034 & 0.040 & 0.032 & 0.000 \\
\hline
\end{tabular}

${ }^{\mathrm{a}}$ The data at $60^{\circ} \mathrm{C} / \mathrm{min}$ are excluded from the average

\section{CONCLUSIONS}

A technique developed by Vandevelde was used to estimate kinetic parameters from thermogravimetric data for Type $\mathrm{C}$ gypsum board. The technique works very well for single isolated reactions. However, if there are simultaneous overlapping reactions, assumptions have to be made about the fraction of the total mass loss that should be attributed to each of the reactions. An attempt was made to separate the two overlapping dehydration reactions of Type $\mathrm{C}$ gypsum board by assuming that the mass loss vs. temperature for the two reactions can be represented by a sigmoid curve. This approach was moderately successful. Perhaps improvements can be made by using another type of function. Parameter estimation techniques based on a GA might work much better in this kind of situation.

\section{REFERENCES}

[1] Lautenberger, C., Rein, G., and Fernandez-Pello, C., (2006) The application of a genetic algorithm to estimate material properties for fire modeling from bench-scale fire test data, Fire Safety Journal 41(3): 204-214, http://dx.doi.org/10.1016/j.firesaf.2005.12.004.

[2] Rein, G., Lautenberger, C., Fernandez-Pello, A., Torero, J., and Urban, D., (2006) Application of genetic algorithms and thermogravimetry to determine the kinetics of polyurethane foam in smoldering combustion, Combustion and Flame 146(1-2): 95-108, http://dx.doi.org/10.1016/j.combustflame.2006.04.013.

[3] Lautenberger, C., A Generalized Pyrolysis Model for Combustible Solids, PhD Thesis, University of California Berkeley, Berkeley, CA, 2007.

[4] Saha, B., Reddy, P., and Ghoshal, A., (2008) Hybrid genetic algorithm to find the best model and the globally optimized overall kinetics parameters for thermal decomposition of plastics, Chemical Engineering Journal 138(1-3): 20-29, http://dx.doi.org/10.1016/j.cej.2007.05.024.

[5] Lautenberger, C., Kim, E., Dembsey, N., and Fernandez-Pello, A., (2009) The role of decomposition kinetics in pyrolysis modeling - Application to a fire retardant polyester composite, Fire Safety Science 9: 1201-1212, http://dx.doi.org/10.3801/IAFSS.FSS.9-1201.

[6] Matala, A., Hostikka, S., and Mangs, J., (2009) Estimation of pyrolysis model parameters for solid materials using thermogravimetric data, Fire Safety Science 9: 1213-1223, http://dx.doi.org/10.3801/IAFSS.FSS.9-1213.

[7] Thomas, G., (2002) Thermal properties of gypsum plasterboard at high temperatures, Fire and Materials 26(1): 37-45, http://dx.doi.org/10.1002/fam.786.

[8] Bénichou, N. and Sultan, M., (2005) Thermal properties of lightweight-framed construction components at elevated temperatures, Fire and Materials 29(3): 165-179, http://dx.doi.org/10.1002/fam.880.

[9] Ghazi Wakili, K., Hugi, E., Wullschleger, L., and Frank, T., (2007) Gypsum board in fire Modeling and experimental validation, Journal of Fire Sciences 25(3): 267-282, http://dx.doi.org/10.1177/0734904107072883. 
[10] Manzello, S., Gann, R., Kukuck, S., and Lenhert, D., (2007) Influence of gypsum board type (X or C) on real fire performance of partition assemblies, Fire and Materials 31(7): 425-442, http://dx.doi.org/10.1002/fam.940.

[11] Craft, S., Isgor, B., Hadjisophocleous, G., and Mehaffey, J., (2008) Predicting the thermal response of gypsum board subjected to a constant heat flux, Fire and Materials 32(6): 333-355, http://dx.doi.org/10.1002/fam.971.

[12] de Korte, A. and Brouwers, H., (2009) Calculation of thermal conductivity of gypsum plasterboards at ambient and elevated temperature, Fire and Materials 34(2): 55-75, http://dx.doi.org/10.1002/fam.1009.

[13] Wullschleger, L. and Ghazi Wakili, K., (2008) Numerical parameter study of the thermal behaviour of a gypsum plaster board at fire temperatures, Fire and Materials 32(2): 103-119, http://dx.doi.org/10.1002/fam.956.

[14] Ghazi Wakili, K. and Hugi, E., (2009) Four types of gypsum plaster boards and their thermophysical properties under fire condition, Journal of Fire Sciences 27(1): 27-43, http://dx.doi.org/10.1177/0734904108094514.

[15] Park, S., Manzello, S., Bentz, D., and Mizukami, T., (2009) Determining thermal properties of gypsum board at elevated temperatures, Fire and Materials 34(5): 237-250, http://dx.doi.org/10.1002/fam.1017.

[16] Vandevelde, P., Detailed Study of the Ignition of Materials - Proposal for a New Measurement and Assessment Method (in Dutch), PhD Thesis, University of Ghent, Ghent, Belgium, 1976.

[17] Manzello, S., Grosshandler, W., and Mizukami, T., (2009) Furnace testing of full-scale gypsum steel stud non-load bearing wall assemblies: Results of multi-laboratory testing in Canada, Japan, and USA, Fire Technology 46(1): 183-200, http://dx.doi.org/10.1007/s10694-009-0090-z. 